\title{
Attitudes Towards the Elderly in Polish Society: Is Knowledge About Old Age and Personal Experiences a Predictor of Ageism?
}

\author{
Marta Podhorecka $\mathbb{D}^{\prime}$ \\ Jakub Husejko' \\ Anna Pyszora ${ }^{2}$ \\ Agnieszka Woźniewicz (1D) \\ Kornelia Kędziora- \\ Kornatowska' \\ 'Department of Geriatrics, Collegium \\ Medicum in Bydgoszcz, Nicolaus \\ Copernicus University in Toruń, Torun, \\ Poland; ${ }^{2}$ Department of Palliative Care, \\ Collegium Medicum in Bydgoszcz, \\ Nicolaus Copernicus University in Toruń, \\ Torun, 85-094, Poland
}

Correspondence: Marta Podhorecka Department of Geriatrics, Collegium Medicum in Bydgoszcz, Nicolaus Copernicus University in Toruń,

University Hospital No. I dr. A. Jurasz, 9

Maria Skłodowska-Curie Street, Torun,

85-094, Poland

Tel +48 52 585-49-00

Email marta.podhorecka@cm.umk.pl
Purpose: The aim of the study was to determine the prevalence and characteristics of ageism in Polish society. In addition, the relationships of opinions with demographic data, knowledge about aging and individual contact with the elderly, in the context of knowledge about their exclusion, were examined.

Patients and methods: The study involved 923 individuals in Poland. Their demographic characteristics were recorded, and all subjects were assessed using Kogan's Attitudes toward Old People (KOAP) scale and asked to complete the Facts on Aging Quiz. Subjects were also asked about their knowledge of the definition of ageism and asked to explain it.

Results: The KOAP scale as a function of predictors was modeled using Bayesian robust linear regression with $t$ distribution. The subjects had a mean (SD) KAOP score of 90.88 (17.41), with the central $50 \%$ of the observations ranging from 83 to 101 points. Three statistically credible relationships with responses to the questionnaires were observed. Respondents attending school had slightly lower average KAOP scores than respondents with other professional status. In addition, FAQ was negatively and moderately related to KAOP, whereas contacts with elderly people were positively and moderately related to KAOP.

Conclusion: Knowledge of aging and contact with elderly individuals significantly affected attitudes and behaviors regarding ageism. Many study subjects were characterized by having unfavorable attitudes towards the elderly.

Keywords: elderly, ageism, KOAP, FAQ, relationships, Poland

\section{Introduction}

Societal aging, a common phenomenon in highly developed countries, is associated with a low birth rate and an increase in life expectancy. Aging of society has been observed in the European Union countries (EU-27), where the number of people aged $\geq 80$ years has been projected to increase 2.5-fold between 2019 and 2100 , from $5.9 \%$ to $14.6 \%{ }^{1}$ Eurostat has reported that Poland is among the top ten countries in which the percentage of the population aged $>65$ years grew between 2009 and 2019. In Poland age discrimination seems to be higher among the youngest respondents, but is also relatively high among older respondents, similar to findings in Germany, Spain and Ukraine. The levels of perceived age discrimination among the oldest respondents were reported highest in countries like the Czech Republic and Russia. Perceived age discrimination was reported to be constant across age groups in Cyprus and Greece, but was much higher in Cyprus and very 
much higher in Greece among the oldest respondents. ${ }^{2}$ The aim of the present study was to determine the scale of ageism in Polish society during the COVID-19 pandemic period.

Increases in the number and percentage of individuals aged $>65$ years requires re-organization of health care systems, the national economy and social relationships. Ageism, first described as a subjective experience relative to the popular notion of a generation gap, Was initially defined as discrimination by the middle-aged group against younger and older groups in society, because the middle-aged group is responsible for the well-being of younger and older age groups, which are perceived as dependent. ${ }^{3}$ The identification of ageism resulted from many years of observation of people's behavior in society and how they automatically categorize others. Although categorization by race and gender was easily identified, the exclusion of people by age was less easily determined. ${ }^{4}$ Ageism is a broad concept covering the problems of prejudice and discrimination against people due to old age $\mathrm{e}^{5}$ and is encountered on the macro and micro levels. It has global effects in the labor market, media, health care, architecture and social policy and can include stereotypical attitudes, lack of alternatives and different methods of communication. ${ }^{6}$ In addition to affecting the functioning and development of societies, ageism is a barrier to the active aging process. Social marginalization of the elderly increases their health problems and disabilities, adversely affecting the burdens on health and social care systems. Policies that make it easier for the elderly to stay healthy, be employed longer and fully participate in society are therefore of great importance. ${ }^{7}$

At the beginning of 2021, the World Health Organization (WHO) published a report on ageism, thus initiating global talks on the occurrence and consequences of ageism in response to changes resulting from the COVID-19 pandemic. ${ }^{8}$ Unfortunately, the WHO report described ageism as a socially acceptable form of discrimination. The role of research and the individual image of each country are also emphasized, as views of age discrimination in each country may differ. Studying the attitudes of society towards the elderly can help in the design of measures that can reduce discriminatory activities.

Contacts between young and old people can be a key to avoiding ageism. The quality of the relationships between grandchildren and grandparents may be the most significant experience affecting young people's attitude towards aging. ${ }^{9}$ One study found that the most important factor influencing youths' views of the elderly was the quality of their contacts with their grandparents. ${ }^{10}$ Good relations between young and old are beneficial to both. Old people might share their wisdom, while younger people could show, for example, how to use new technologies. Intergenerational interactions support both and provide opportunities to build positive attitudes towards the elderly.

Research to date has shown a relationship between level of knowledge about the aging process and attitudes towards the elderly. ${ }^{11-13}$ In the Polish literature, however, there are no current data on social attitudes towards the elderly. Studies are needed due to predicted demographic changes and the need to prevent possible occurrences of ageism. The primary aim of the present study was to determine the scale of ageism in Polish society. Additionally, as part of an in-depth analysis, we asked the following research questions:

- Do attitudes toward the elderly differ by age, sex, level of education, place of residence, marital status, or professional situation?

- Do attitudes toward the elderly differ by represented knowledge about aging?

- Do attitudes toward the elderly differ depend on respondents' contact with the elderly in their private and professional lives?

- Is the concept of ageism familiar to the respondents? If so, how do they define it?

\section{Materials and Methods Research Design}

This was a cross-sectional internet-based survey conducted in Poland during the first two weeks of February 2021.

\section{Subjects}

Participation was voluntary and anonymous. Anonymous online questionnaires were distributed to individuals with the help of the Survgo system, with 923 subjects completing these questionnaires. The entire population of Poland is estimated to be $38,265,000$ persons. The number of respondents participating in this study was representative, but due to the online nature of the research, they cannot be treated as such.

\section{Instruments}

Participants were asked to complete four surveys. The first was on demographic characteristics, including age, sex, 
place of residence, marital status, level of education, professional situation, length of service, and gross annual income. The second and third surveys, the Polish versions of the Kogan's Attitudes toward Old People (KOAP) scale and the Facts on Aging Quiz (FAQ), are often used in research on ageism. ${ }^{14}$ The KAOP is a 34 -item questionnaire, each of which was scored on a six-point Likert scale, where 1 indicates strongly disagree and six indicates strongly agree, with half the questions being negative and the other half positive. ${ }^{15}$ Total scores ranged from 34-204 points, where higher scores indicate a more positive attitude towards the elderly. ${ }^{16}$ Cronbach's alpha was found to be 0.73 and 0.83 for the positive and negative scales, respectively. ${ }^{15}$

The FAQ is a 25 -item questionnaire addressing knowledge about old age, with subjects answering each statement as true or false. ${ }^{17}$ The tool FAQ statements that cover knowledge about the physical, psychological and social characteristics associated with old age. Each correct answer was scored as one point, with total scores ranging from $0-25$ and higher scores indicating greater knowledge of old age. Cronbach's alpha ranged from 0.45 to $0.66 .{ }^{18}$

The fourth survey consisted of a proprietary questionnaire on personal experiences with the elderly and included the questions in Table 1. Subjects were also asked to define the term ageism.

\section{Ethical Considerations}

The study was approved by the Bioethics Committee of the Nicolaus Copernicus University Collegium Medicum in Bydgoszcz, Poland (KB 83/2021). The research was conducted in accordance with the Helsinki Declaration All participants provided informed consent for the research.

\section{Procedure}

Surveys were sent to participants via web forms due to the current global pandemic. The survey was developed by the research team via the media and on the Survgo internet platform, on which the survey itself was constructed.

The participants were assured of the confidentiality of information and their participation was voluntary and anonymous. A random sample, taking both sex and age into account, was selected. Only questionnaires fully completed by adult respondents were included in the analysis.

\section{Data Analysis}

Data were analyzed using R 4.0.2 software. ${ }^{19}$ KAOP score as a function of predictors was modeled using Bayesian
Table I The Original Questionnaire "Contact with the Elderly"

\begin{tabular}{|c|l|l|}
\hline \multicolumn{2}{|c|}{ Contact with the Elderly } \\
\hline I & $\begin{array}{l}\text { Do you live or have you ever lived with } \\
\text { an elderly person? }\end{array}$ & $\begin{array}{l}\text { a) Yes } \\
\text { b) No }\end{array}$ \\
\hline 2 & $\begin{array}{l}\text { Do you have contact with an elderly } \\
\text { person in your private life? }\end{array}$ & $\begin{array}{l}\text { a) Yes, I live with an } \\
\text { elderly person } \\
\text { b) Yes, several times } \\
\text { a week } \\
\text { c) Only at } \\
\text { ceremonies } \\
\text { d) Occasionally } \\
\text { e) Not at all }\end{array}$ \\
\hline 3 & $\begin{array}{l}\text { Do you have contact with people over 65 } \\
\text { at work? }\end{array}$ & $\begin{array}{l}\text { a) Yes } \\
\text { b) No } \\
\text { c) I do not have the } \\
\text { opportunity }\end{array}$ \\
\hline 4 & $\begin{array}{l}\text { Are you in contact with elderly people } \\
\text { who are not family members? }\end{array}$ & $\begin{array}{l}\text { a) Yes } \\
\text { b) No } \\
\text { c) I do not have the } \\
\text { opportunity }\end{array}$ \\
\hline & $\begin{array}{l}\text { How important are contacts with the you? } \\
\text { a) Very important } \\
\text { b) Important } \\
\text { c) It does not } \\
\text { matter } \\
\text { d) Not important }\end{array}$ \\
\hline
\end{tabular}

robust linear regression with $t$ distribution. ${ }^{20}$ In each of the analyses, a "no opinion" response was deemed equivalent to a neutral attitude and was defined as a midpoint of the scale. Ordered categorical predictors were coded with orthogonal linear contrast; unordered categorical predictors were coded with sum-to-zero contrast; and continuous predictors were entered into a model on a standardized scale. In Bayesian statistics the inference was based on analyzing the posterior probability distributions of model parameters (eg, regression weights), obtained by integrating likelihood (data) with prior probability distributions. Regression weights were defined as statistically credible when $95 \%$ credible intervals $(95 \% \mathrm{CI})$ of the posterior distribution excluded zero. ${ }^{21}$ The means of the posterior distributions were defined as the point estimates of the effects. Default improper flat priors were used for the regression weights. To investigate the relationship between a dependent variable and a credible predictor, the predicted marginal means with the corresponding 95\% CIs were presented as figures. These values represented the median posterior distribution of the predicted KOAP values. 
To approximate posterior distributions of the models, a Markov Chain Monte Carlo (MCMC), sampling procedure was performed using the brms package in R software. ${ }^{21}$ Six parallel chains were used, each consisting of 8000 samples, with 4000 samples used as a warm up period and every tenth sample recorded, resulting in a total of 2400 recorded samples. The sampling procedure was efficient and resulted in well mixed, not autocorrelated, chains and unimodal posteriors. Model accuracy was assessed with posterior predictive checks. There were no missing values in the data.

\section{Results}

The characteristics of the study participants are presented in Table 2.

The mean (SD) KAOP score of the sample was 90.88 (17.41), with the central $50 \%$ of the observations ranging from 83 to 101 points. Model coefficients of linear regression with KAOP as a dependent variable are summarized in Table 3, whereas model predictions for the credible predictors are presented in Figure 1. Three statistically credible relationships with responses to the questionnaires were observed. Respondents reporting a professional status as "at school" had slightly lower average KAOP scores than respondents with other professional status. In addition, FAQ was negatively and moderately related to KAOP, whereas contacts with elderly people were positively and moderately related to KAOP.

\section{Discussion}

Ageism has been defined as negative or positive stereotypes, prejudices and/or discrimination (or benefit) associated with older people based on their actual or perceived chronological age. Ageism may be latent or explicit and may be expressed at the micro, meso or macro level. ${ }^{22}$ Therefore, studies assessing ageism in a society require a large number of respondents, as in the present study. Ageism, however, is very complex and involves social relationships on many levels. The KAOP scale and the FAQ seemed excellent tools for these measurements, as they allowed multi-dimensional assessment of the attitudes of the respondents towards elderly individuals, and their results can be compared with previous. Only one study to date has assessed ageism throughout Poland. That study used the KOAP and the Morris Rosenberg SelfAssessment Questionnaire to measure self-acceptance and social perception of seniors, along with several other
Table 2 Characteristics of Study Participants ( $N=923)$

\begin{tabular}{|c|c|c|}
\hline Sex & Number & Percentage \\
\hline Female & 475 & 51.46 \\
\hline Male & 448 & 48.54 \\
\hline \multicolumn{3}{|l|}{ Age, yr } \\
\hline $18-29$ & 251 & 27.19 \\
\hline $30-39$ & 233 & 25.24 \\
\hline $40-49$ & 234 & 25.35 \\
\hline $50 \geq$ & 205 & 22.21 \\
\hline \multicolumn{3}{|l|}{ Place of residence } \\
\hline Village & 163 & 17.66 \\
\hline$<50 \mathrm{~K}$ & 207 & 22.43 \\
\hline$<100 \mathrm{~K}$ & 159 & 17.23 \\
\hline$<250 \mathrm{~K}$ & 138 & 14.95 \\
\hline$>250 \mathrm{~K}$ & 256 & 27.74 \\
\hline \multicolumn{3}{|l|}{ Marital status } \\
\hline Single & 158 & 17.12 \\
\hline Informal relationship & 225 & 24.38 \\
\hline Married & 482 & 52.22 \\
\hline$S / D / W$ & 58 & 6.28 \\
\hline \multicolumn{3}{|l|}{ Education } \\
\hline Elementary & 28 & 3.03 \\
\hline Vocational & 98 & 10.62 \\
\hline Secondary & 407 & 44.1 \\
\hline Higher & 390 & 42.25 \\
\hline \multicolumn{3}{|c|}{ Professional situation } \\
\hline At school & 73 & 7.91 \\
\hline Unemployed & 81 & 8.78 \\
\hline Employed & 686 & 74.32 \\
\hline Pensioner & 83 & 8.99 \\
\hline \multicolumn{3}{|l|}{ Annual income } \\
\hline 0-20.999 & 153 & 16.58 \\
\hline $21.000-40.999$ & 220 & 23.84 \\
\hline $41.000-60.999$ & 215 & 23.29 \\
\hline $61.000-80.999$ & $15 \mid$ & 16.36 \\
\hline
\end{tabular}

(Continued) 
Table 2 (Continued).

\begin{tabular}{|l|l|l|}
\hline Sex & Number & Percentage \\
\hline 81.000 and more & 117 & 12.68 \\
\hline Refuse to answer & 67 & 7.26 \\
\hline
\end{tabular}

questionnaires. These participants had an average 126.48 points on the KAOP, with the highest scores attained by women aged $<60$ years, who were in a relationship, had completed higher education and were in a good financial situation. ${ }^{23}$ In contrast, the participants in the present study had an average 90.88 points on the KAOP.
More research in Poland on attitudes towards the elderly has focused on students, as young people who are just starting to actively participate in society. The present study found that respondents who were "at school" had slightly lower average KAOP scores than respondents with other professional status. Similar results were observed in a study of medical and nursing students living in eastern Poland, with only $48 \%$ of future medics being willing to work with elderly people in the future. ${ }^{24}$ In contrast, most people supplementing secondary education at the Complex of Schools for Adults in Brzesko (Poland) had positive attitudes towards elderly people and sufficient knowledge about aging and diseases of old age. ${ }^{25}$ Young graduates of

Table 3 Results of Bayesian Robust Linear Regression with KAOP Score as a Dependent Variable

\begin{tabular}{|c|c|c|c|c|}
\hline & B & SE & LI & UI \\
\hline Intercept & -0.1 & 0.07 & -0.25 & 0.05 \\
\hline Sex & -0.03 & 0.03 & -0.09 & 0.03 \\
\hline Age & 0.06 & 0.07 & -0.08 & 0.21 \\
\hline Place of residence & -0.01 & 0.06 & -0.12 & 0.1 \\
\hline Marital status - Single & -0.11 & 0.08 & -0.27 & 0.05 \\
\hline Marital status - Informal relationship & -0.11 & 0.08 & -0.27 & 0.04 \\
\hline Marital status - Married & -0.15 & 0.12 & -0.37 & 0.09 \\
\hline Education & -0.08 & 0.08 & -0.24 & 0.08 \\
\hline Professional status (at school) & -0.23 & 0.09 & -0.4 & -0.06 \\
\hline Professional status (unemployed) & 0.19 & 0.07 & 0.05 & 0.33 \\
\hline Professional status (employed) & -0.06 & 0.05 & -0.17 & 0.04 \\
\hline FAQ & -0.34 & 0.03 & -0.39 & -0.29 \\
\hline Living with an elderly person & 0.03 & 0.03 & -0.03 & 0.09 \\
\hline Personal contacts with elderly people & -0.02 & 0.09 & -0.2 & 0.15 \\
\hline Professional contacts with elderly people (yes) & -0.04 & 0.04 & -0.12 & 0.04 \\
\hline Professional contacts with elderly people (no) & 0.07 & 0.04 & -0.01 & 0.14 \\
\hline Contacts with elderly people outside the family (yes) & -0.05 & 0.04 & -0.13 & 0.03 \\
\hline Contacts with elderly people outside the family (no) & -0.07 & 0.04 & -0.15 & 0.01 \\
\hline Relevance of contacts with elderly people & 1.03 & 0.1 & 0.83 & 1.22 \\
\hline$\Sigma$ & 0.65 & 0.03 & 0.6 & 0.71 \\
\hline $\mathrm{N}$ & 5.02 & 0.89 & 3.63 & 7.06 \\
\hline Bayesian $\mathrm{R}^{2}$ & 0.26 & 0.02 & 0.22 & 0.3 \\
\hline
\end{tabular}

Notes: $\beta$ and SE are posterior mean and standard error of the mean, respectively. LI and Ul are lower and upper boundaries of the $95 \%$ credibility interval. The [n] symbol indicates the nth coefficient of a sum-to-zero contrast for a categorical predictor. Bolded rows indicate statistically credible regression weights. $\sigma$ and $v$ are scale and normality parameters of the $t$ distribution, respectively. 

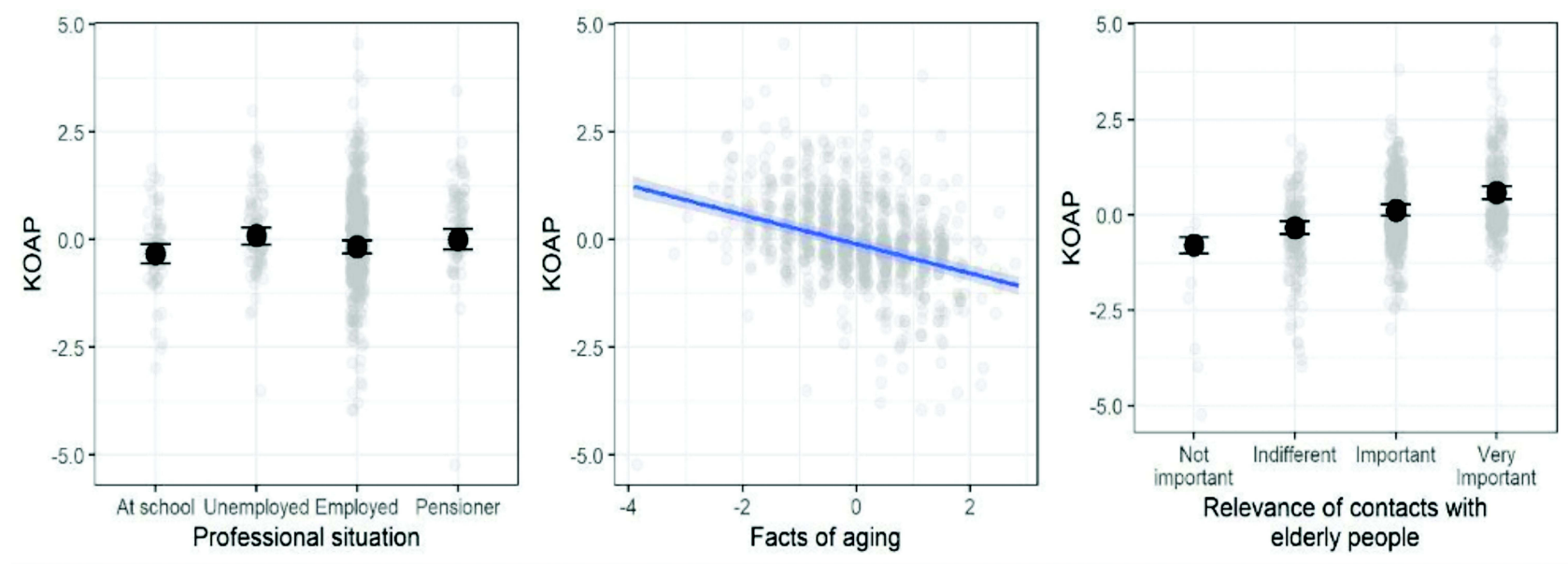

Figure I Posterior medians (points and blue line) of the predicted mean KAOP scores as a function of credible predictors. Vertical lines and shaded area are $95 \%$ credible intervals.

Note: KAOP and Facts of aging are shown on standardized scales. Grey transparent points show data.

the Kazimierz Wielki University in Bydgoszcz (Poland) also had a positive attitude toward elderly people, while also expressive negative attitudes towards seniors of increasing age. ${ }^{26}$ The young adults participating in this study were not involved in the medical professions, suggesting that people with non-medical professions have a more positive attitude towards seniors than future health care workers in Poland.

The present study also found that contacts with elderly people were positively and moderately related to increased KAOP scores. Similar findings were observed in a study in Poznań (Poland), where a positive correlation was observed between spending more time with elderly people and KAOP scores. Additionally, self-esteem, as measured using the Rosenberg Self-Esteem Scale (SES) was positive correlated with the perception of older age. In contrast, assessment of the elderly by the respondents was unrelated to marital status, place of residence or level of education, ${ }^{16}$ although a previous study found that KAOP score decreased with the age of the respondents. ${ }^{26}$ Additional studies are therefore needed to assess the relationship between age and acceptance of elderly people.

The present study also found that knowledge of and contact with elderly people significantly affected respond behavior concerning ageism. In contrast, the frequency of intergenerational contact did not positively correlate with young people's attitudes and behavioral intentions towards the elderly, whereas the latter was associated with quality of life. ${ }^{27}$ Cooperative contact with individual members of an out-group has been hypothesized to lead to more positive attitude towards the out-group as a whole, within the context of interage interactions. That study confirmed that self-reported favorable quality, but not frequency, of contact was significantly related to more positive attitudes toward the elderly in college-aged participants. ${ }^{28,29}$ Moreover, another study found that, over the course of a semester, students' knowledge about and attitudes toward the elderly improved significantly. ${ }^{30}$

Research on the relationship between the level of knowledge about aging and ageism has yielded conflicting results. For example, a study of nursing students in Greece showed that attitudes towards older people were more positive among students in their last years than in those starting their education. ${ }^{31}$ The present study showed a negative correlation between the level of knowledge about aging (FAQ score) and ageism (KAOP score). However, it should be emphasized that the KAOP scores in this study were high, indicating positive attitudes of the studied group towards the elderly. Unfortunately, the present analysis did not include an assessment of aging anxiety. A study conducted among students of nursing in Zanzibar showed that most of the respondents had a positive attitude about elderly persons, but a low level of knowledge about caring for them, ${ }^{32}$ further indicating a negative relationship between the level of knowledge and positive attitudes towards the elderly. In contrast, another study found that greater knowledge about the aging process was associated with fewer negative attitudes towards the elderly. ${ }^{33}$ The main predictors of ageism have been reported to be a high level of anxiety related to aging, a low level of knowledge about aging and a limited number of contacts with the elderly. ${ }^{12}$ Misconceptions about the aging process were found to 
play a significant role in creating negative attitudes towards the elderly, thus increasing the fear of aging ${ }^{13}$ and playing an important role in creating negative attitudes towards the elderly. The present results were therefore extremely surprising, especially because similar correlations were not observed earlier. Additional studies are needed to verify this relationship.

Ethnic and cultural affiliation with particular groups and their influence on self-esteem and perception of the elderly require further analysis, especially in societies living in developed countries, which are characterized by increasing cultural diversity. Interviews of 17 Somali elders, nine women and eight men, living in Canada showed that most of respondents rated the conditions provided to seniors as positive, although men were more critical than women in regard to the challenges of aging in Canada. ${ }^{34}$ Despite our study not including a cultural factor, the increasing cultural diversity in Polish society ${ }^{35}$ suggests that culture should be considered in future analyses. Attitudes towards the elderly are not determined by cultural affiliation, inasmuch as the approach of individual respondents is a more statistically significant factor than belonging to a specific cultural group. $^{36}$

\section{Limitations of the Study}

The present study had several limitations. The main limitation was data collection via the internet, thus excluding people who were not active online and preventing the generalization of our the results to the entire Polish population. The COVID-19 pandemic, however, limited access to respondents, making online data collection the only feasible option. Therefore, there is a need for similar research after the end of the COVID-19 pandemic.

\section{Conclusion}

As part of the presented research, we can conclude that:

1. Greater knowledge about aging influences negative attitudes towards older people.

2. Younger people who are still in school have more unfavorable attitudes towards older people.

3. People who are in greater contact with the elderly have fewer negative attitudes towards this age group.

Better attitudes toward elderly people can be promoted by educational processes, programs or projects that include meetings with the elderly and presenting basic knowledge about the aging process. However, this issue requires more detailed research involving large groups of participants. Future studies should consider different age and educational levels and comparisons of the present results with those collected after the pandemic period. Application of the findings, that knowledge of and contact with the elderly significantly affects behavior that can be considered ageism, should convince people involved in education to integrate young people with the elderly.

\section{Disclosure}

The authors report no conflicts of interest related to this work.

\section{References}

1. Eurostat Statistics Explained. Population structure and ageing; August, 2020. Available from: https://ec.europa.eu/eurostat/statisticsex-plained/index.php?title=Population_structure_and_ageing\#The share_of_elderly_people_continue_to_increase. Accessed December $13,2021$.

2. Bratt C, Abrams D, Swift HJ, Vauclair CM, Marques S. Perceived age discrimination across age in Europe: from an ageing society to a society for all ages. Dev Psychol. 2018;54(1):167-180.

3. Butler RN. Age-Ism: another form of bigotry. Gerontologist. 1969;9 (4):243-246

4. Nelson TD. Ageism: prejudice against our feared future self. J Soc Issues. 2005;61(2):207-221

5. Burnes D, Sheppard C, Henderson CR Jr, et al. Interventions to reduce ageism against older adults: a systematic review and meta-analysis. Am J Public Health. 2019;109(8):e1-e9.

6. Minichiello V, Browne J, Kendig H. Perceptions and consequences of ageism: views of older people. Ageing Soc. 2000;20(3):253-278.

7. Walker A, Foster L. Active ageing: rhetoric, theory and practice. In: Ervik R, Linden TS, editors. The Making of Ageing Policy. London: Edward Elgar; 2013:27-52.

8. World Health Organization. Global report on ageism; March 18, 2021. Available from: https://www.who.int/publictions/i/item/globalreport-on-ageism. Accessed December 13, 2021.

9. Del Carmen Requena M, Swift HJ, Naegele L, et al. Educational methods using intergenerational interaction to fight ageism. In: Ayalon L, Tesch-Römer C, editors. Contemporary Perspectives on Ageism. Generva: Springer; 2018:383-402.

10. Society for Research in Child Development. Quality of contact with grandparents is key to youths' views of ageism. ScienceDaily; December 19, 2017. Available from: https:/www.sciencedaily.com/ releases/2017/12/171219091328. Accessed December 132021.

11. Shiovitz-Ezra S, Ayalon L, Brodsky J, Doron I. Measuring ageism based on knowledge, attitudes and behavior: findings from an Israeli pilot study. Ageing Int. 2016;41(3):298-310.

12. Cooney C, Minahan J, Siedlecki KL. Do feelings and knowledge about aging predict ageism? J Appl Gerontol. 2021;40(1):28-37.

13. Rababa M, Hammouri AM, Hweidi IM, Ellis JL. Association of nurses' level of knowledge and attitudes to ageism toward older adults: cross-sectional study. Nurs Health Sci. 2020;22(3):593-601.

14. Ayalon L, Dolberg P, Mikulionienè S, et al. A systematic review of existing ageism scales. Ageing Res Rev. 2019;54:100919.

15. Kogan N. Attitudes toward old people: the development of a scale and an examination of correlates. J Abnorm Soc Psychol. 1961;62 (1):44-54. 
16. Strugała M, Talarska D, Mińska M. Postrzeganie starości i starzenia się przez osoby dorosłe i w wieku podeszłym. Pielęgniarstwo Pol. 2016;3(61):376-382.

17. Palmore EB. The Facts on Aging Quiz: A Handbook of Uses and Results. Geneva: Springer; 1988.

18. Faílde Garrido JM, Dapía Conde MD, Vázquez Vázquez MA, Vázquez Rodríguez L. Are older adults' leisure patterns consistent with the active ageing model? The influence of the ageist stereotypes. Social Pol Society. 2021. doi:10.1017/S1474746421000221.

19. R Core Team. R: a language and environment for statistical computing; 2020. Available from: https://www.R-project.org/. Accessed December 29, 2021.

20. Kruschke J. Doing Bayesian Data Analysis: A Tutorial with R, JAGS, and Stan. Academic Press; 2014.

21. Bürkner PC. brms: an R package for Bayesian multilevel models using Stan. J Stat Softw. 2017;80(1):1-28.

22. Iversen TN, Larsen L, Solem PE. A conceptual analysis of ageism. Nordic Psychol. 2009;61(3):4-22.

23. Wysokiński M, Fidecki W, Plech T, Wrońska I, Pawelec MK, Dziedzic B. Perception of old age by the inhabitants of Poland. Int J Environ Res Public Health. 2020;17(7):2389.

24. Dobrowolska B, Jędrzejkiewicz B, Pilewska-Kozak A, et al. Age discrimination in healthcare institutions perceived by seniors and students. Nurs Ethics. 2019;26(2):443-459.

25. Wojcieszek A, Majda A, Nawalana A. The attitudes of people in supplementary secondary education towards elderly people. Nursing Prob. 2013;21(4):496-503.

26. Trempała J, Zając-Lamparska L. Postawy wobec osób starszych: różnice międzypokoleniowe. Przegląd Psychologiczny. 2007;50 (4):447-462.
27. Bousfield C, Hutchison P. Contact, anxiety, and young people's attitudes and behavioral intentions towards the elderly. Educ Gerontol. 2010;36(6):451-466.

28. Allport GW. The Nature of Prejudice. Cambridge: Addison-Wesley; 1954.

29. Angiullo L, Whitbourne SK, Powers C. The effects of instruction and experience on college students' attitudes toward the elderly. Educ Gerontol. 1996;22(5):483-495.

30. Allan LJ, Johnson JA. Undergraduate attitudes toward the elderly: the role of knowledge, contact and aging anxiety. Educ Gerontol. 2008;35 (1):1-14.

31. Lambrinou E, Sourtzi P, Kalokerinou A, Lemonidou C. Attitudes and knowledge of the Greek nursing students towards older people. Nurse Educ Today. 2009;29(6):617-622.

32. Muhsin AA, Munyogwa MJ, Kibusi SM, Seif SA. Poor level of knowledge on elderly care despite positive attitude among nursing students in Zanzibar Island: findings from a cross-sectional study. BMC Nurs. 2020;19:96.

33. Donizzetti AR. Ageism in an aging society: the role of knowledge, anxiety about aging, and stereotypes in young people and adults. Int $J$ Environ Res Public Health. 2019;16(8):1329.

34. Lagacé M, Charmarkeh H, Grandena F. Cultural perceptions of aging: the perspective of Somali Canadians in Ottawa. J Cross Cult Gerontol. 2021;27(4):409-424.

35. Mayblin L, Valentine G, Winiarska A. Migration and diversity in a post-socialist context: creating integrative encounters in Poland. Environ Plan A Econ Space. 2016;48(5):960-978.

36. Zhang X, Xing C, Guan Y, et al. Attitudes toward older adults: a matter of cultural values or personal values? Psychol Aging. 2016;31(1):89-100.
Psychology Research and Behavior Management

\section{Publish your work in this journal}

Psychology Research and Behavior Management is an international, peer-reviewed, open access journal focusing on the science of psychology and its application in behavior management to develop improved outcomes in the clinical, educational, sports and business arenas. Specific topics covered in the journal include: Neuroscience, memory and decision making; Behavior modification and management; Clinical

\section{Dovepress}

applications; Business and sports performance management; Social and developmental studies; Animal studies. The manuscript management system is completely online and includes a very quick and fair peer-review system, which is all easy to use. Visit http://www. dovepress.com/testimonials.php to read real quotes from published authors. 